\title{
Understanding the risks from extreme rainfall
}

Mari R. Tye CEng, PhD, MICE

Project Scientist, MMM, National Center for Atmospheric Research, Boulder, CO, USA

Empirical engineering design based on single 'fail safe' target return periods is not appropriate in a non-stationary future climate. Extreme responses to rainfall are very likely to increase under climate change, posing increased hazards to critical infrastructure and the most vulnerable sectors of society. Structures with long life spans require reasonable estimates of the hazards that will be faced now and in the future, necessitating some assessment of future rainfall extremes. Such challenges are not new. Although future climate conditions may be unprecedented, techniques to optimise water management and minimise risk in more extreme climate regimes are not. Designs that account for future climatic extremes could benefit from other countries' experiences of highly variable extreme rainfall. This paper synthesises the physical mechanisms leading to extreme rainfall, and their representation in climate models. It then summarises recent observed changes in extreme rainfall and the anticipated future changes in response to changing climate conditions. Finally, it discusses ways in which different measures of extreme rainfall, such as seasonality and intensity, can be used to inform designs for future flood resilience.

\section{Introduction}

Climatic extremes such as flood, drought, windstorm and heat wave pose multi-dimensional hazards to critical infrastructure and the most vulnerable sectors of society, and are expected to become worse with climate change (IPCC, 2012) and the increasing location of people in high-risk areas. Riverine (fluvial) and surface water (pluvial) flooding were identified as the greatest threats to the UK (Defra, 2012) implying that the UK is highly sensitive to extreme rainfall (Krebs et al., 2010; Met Office, 2011). The Association of British Insurers estimated that the insured costs of UK flooding over Christmas and the New Year period 2013/2014 were $£ 426$ million (ABI, 2014); and the Committee on Climate Change cautioned that current flood defence spending plans will lead to $£ 3$ billion avoidable damages over the next 10 years (Adaptation Sub-Committee Secretariat, 2014). Yet, research programmes in engineering have only recently started to address the issue of adaptation planning for complex meteorological hazards, even though this has been identified as an urgent requirement, with respect to effective risk and financial management (Krebs et al., 2010; Stern, 2007).

Although increased development on flood plains may be in part responsible for the recent rise in flood damages, recent studies (e.g. Blöschl and Montanari, 2010) point towards an increase in heavy rainfall incidences (leading to floods) in comparison with previous decades. Many flood 'hot spots' around the world have experienced several devastating floods in the most recent decade (Figure 1), more than would be expected from natural variability alone (Min et al., 2011). Each of the events had enormous social and financial consequences and projections of future climate responses, together with increased exposure, indicate that this is likely to become worse (Zhang et al., 2011).

There has been a substantial increase in the impacts of heat waves, droughts and floods (e.g. Munich RE, 2013), and climate projections indicate that these will increase in the UK in the future (IPCC, 2013; Murphy et al., 2009). Yet appropriate risk and hazard management strategies cannot be devised without a proper understanding of the potential impacts and vulnerability of infrastructure and society to extreme rainfall under current climatic conditions. Traditional risk management strategies often examine a single hazard, such as the annual maximum daily rainfall total, even though these are insufficient to detect the conditions that may lead to a significant impact (Leonard et al., 2014). Thus, it is important to consider several aspects of a hazard and the different responses that may enhance vulnerability and risks.

Many organisations and governments worldwide are endeavouring to understand the true impacts, both current and future, of climate change. The UK Committee on Climate Change is one such organisation aiming to identify the observable impacts in different sectors (e.g. health, agriculture), their secondary impacts on other sectors and their likely future evolution, using the UK climate change projections (Murphy et al., 2009). The first phase of a similar exercise was completed in New York prior to the arrival of Hurricane Sandy (Rosenzweig et al., 2011), identifying many areas that 


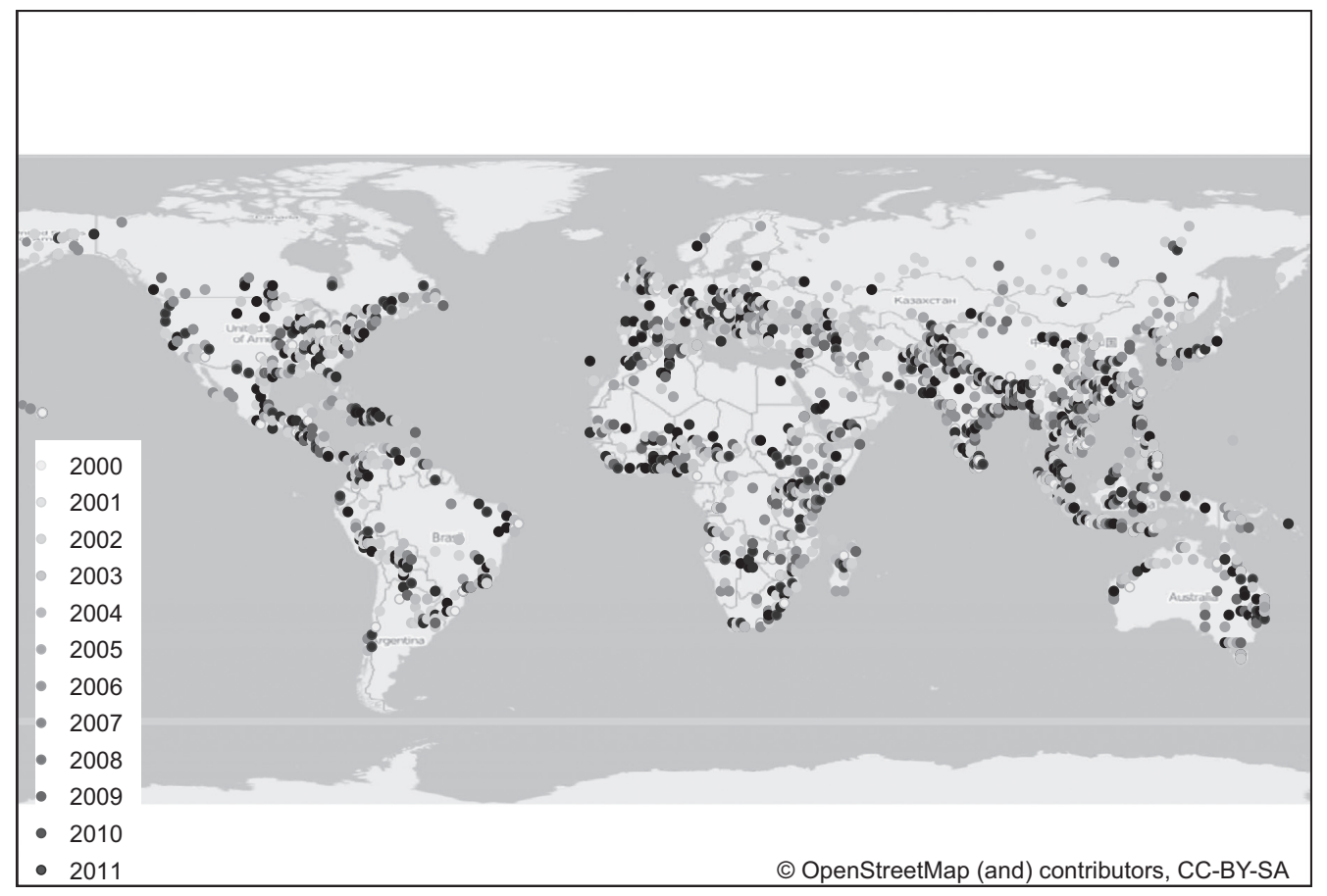

Figure 1. Recurrence of global large flood events 2000-2011 identified from news, government, instrument and remote sensing sources (produced from data available at Brackenridge (2011))

were subsequently affected. The difficulty with implementing these assessments is that changes in mean climate behaviour are better understood and documented than changes in extreme weather, yet the damage caused by the latter has the greatest impact on society. The United Nations estimates that by 2050 approximately 6.5 billion people will live in cities that are highly vulnerable to natural hazards such as hurricanes and tidal surges (Sundermann et al., 2013). As a result, it is critical to understand the risks posed by extreme weather, their natural variability and the likely changes in the hazards and the impacts to improve resilience.

'Resilient design' is a concept that is gaining popularity, particularly among politicians and budget holders, yet it is often confounded in use with 'resistant design'. The Oxford English Dictionary defines resilience as 'the capacity to recover quickly from difficulties; toughness', while resistance is defined as 'the ability not to be affected by something, especially adversely'. The two are very different approaches: the latter implies that a system is 'fail safe' and engenders a false belief of minimal impact, whereas the former accepts that failure will occur and aims to minimise the consequences. Resilience is interpreted here as the ability to recover to a stable state of operation after systematic failure and does not include immediate corrective responses to a high-impact event (e.g.
O'Connell and Hall, 2007). Resilient design adopts a tiered approach, incorporating a degree of resistance to failure, planned redundancy to minimise the damage and disruption caused by an extreme event, and an approach to facilitate recovery. These designs also balance economic, social and political constraints through on-going two-way communication and collaboration.

The current paper summarises current scientific knowledge for those with limited expertise in meteorology or climate science, to demonstrate that flexibility in design will help improve resilience to future flooding. It outlines the different influences on extreme rainfall in the UK, then outlines the models and tools used to estimate future hazards. It then summarises recent research on the changes in extreme rainfall characteristics before outlining the likely consequences for flood hydrology and some possible mitigation measures.

\section{Background science}

Climate change is a continuous process, arising from atmospheric responses to internal perturbations (i.e. natural variability) and to external forcing, such as volcanic activity or solar variability, in addition to anthropogenic influences. However, these atmospheric responses are changing more rapidly than previously experienced as a consequence of the 
post-industrial anthropogenic forcing (IPCC, 2013). While the primary consequences of increased mean global temperature are well understood - such as increased drought periods, rapid melting of icecaps and glaciers, and an enhanced hydrological cycle - establishing the point at which the primary responses differ from natural climate variability and display irrefutable evidence of a change in climate is a subject of much research. For example, while it is now certain that the land surface air temperatures have increased everywhere since the late twentieth century, particularly since the 1970 s, there is only medium confidence that heavy rainfall events have changed over North America and Europe (IPCC, 2013). There will always be a new extreme event, possibly unforeseeable, to break previous records, and there is a natural tendency for extremes to cluster together; thus, it is often difficult to discern the difference between natural climatic variability and long-term changes in behaviour of extreme events over recent time periods.

Extreme value analysis applied to very rare, highly damaging events may be limited by the paucity of records, but it does serve to put some of the unforeseen most extreme events into context and identify the likely return frequency for use in practical applications such as flood defence design (Mandelbrot and Wallis, 1968). However, the stationarity assumptions that were once appropriate for estimating the return frequency of severe events can no longer be applied indiscriminately (Milly et al., 2008), as climate change continues to enhance natural climatic variability and increase the extremes of the hydrological cycle (Trenberth, 2011).

To understand the probability of an extreme rainfall event, it is first necessary to understand the governing weather systems that generate these extremes. Heavy and extreme rainfall can arise from two different scales of rain-bearing systems: synoptic scale $\left(100-1000 \mathrm{~km}^{2}\right)$ and meso scale $\left(1-10 \mathrm{~km}^{2}\right)$.

Synoptic scale: mid-latitude frontal depressions frequently affect the UK and are most common in winter. Frontal depressions are usually generated over the North Atlantic, are often very large, can be fast travelling and can be enhanced by the remnants of tropical cyclones. During the summer, frontal depressions often contain embedded convection cells that generate intense areas of localised rainfall and exacerbate flooding. Severe local cyclones, also called windstorms and Arctic hurricanes, result in substantial wind damage and widespread flooding.

Meso scale: these systems are more frequent in the summer or where high-temperature differentials occur, such as in the foothills of highly mountainous areas. Thunderstorms or convective cloud systems are the most common cause of UK summer storms and are often short lived and very small in area, making them particularly hard to reproduce in weather prediction or climate models. These systems produce some of the highest rainfall rates in northwest Europe.

Different air masses have particular characteristics related to available convective energy, air pressure and humidity, which drive different weather conditions. Although extremes of wind and rain may not often occur at the same time, extreme rainfall events are governed by synoptic scale circulations where the cyclonic winds draw additional rainfall into the water column from a radius of three to five times greater than the rainfall region (Trenberth, 2011).

The UK is situated between the polar jet $\left(50-60^{\circ} \mathrm{N}\right)$ and the sub-tropical jet $\left(30^{\circ} \mathrm{N}\right)$, at the boundary of different air masses. The polar jet tends to shift towards the equator during the winter, causing Atlantic depressions to deepen and increase the associated rainfall. Although the years 2011 to 2013 were associated with anomalously southerly polar jet locations and more frequent rainfall, there is evidence to suggest that the polar jet has moved further north since the 1970s (IPCC, 2013), and by corollary the North Atlantic storm track, possibly leading to a greater north-south divide in wet and arid conditions across the UK in the future. Figure 2 illustrates the movement of air masses associated with the jet stream and the principal wind systems.

Recent years are notable for exceptionally strong La Niña and El Niño conditions, which are associated with extreme weather conditions in different parts of the world, as well as particularly strong North Atlantic sea level pressure differentials reflected in the North Atlantic oscillation index. However, large-scale weather patterns are only one of several explanatory variables in a highly complex system governing severe and extreme storm conditions. The UK Adaptation Sub-Committee recently identified a lack of acknowledgement of climate-related risks in major strategic decisions in the UK (Krebs et al., 2011), even though flexible adaptation actions that are implemented now will limit future potential damages and may also bring short-term benefits. To characterise the current risks from extreme rainfall and their future evolution, and so improve resilience, it is necessary to incorporate knowledge of their dependence on atmospheric processes and relationships with other meteorological conditions and teleconnections into the decision-making process.

\section{Climate modelling}

Given the non-stationarity of the climate, from short-term diurnal cycles to seasonal and multi-annual fluctuations, it is important to use sufficiently long time series of high-quality rainfall observations to distinguish natural variability from other divergent behaviour. Given the complexity of the climate system and responses, simple extrapolation of observed trends into the future is not judicious. Observational records provide 


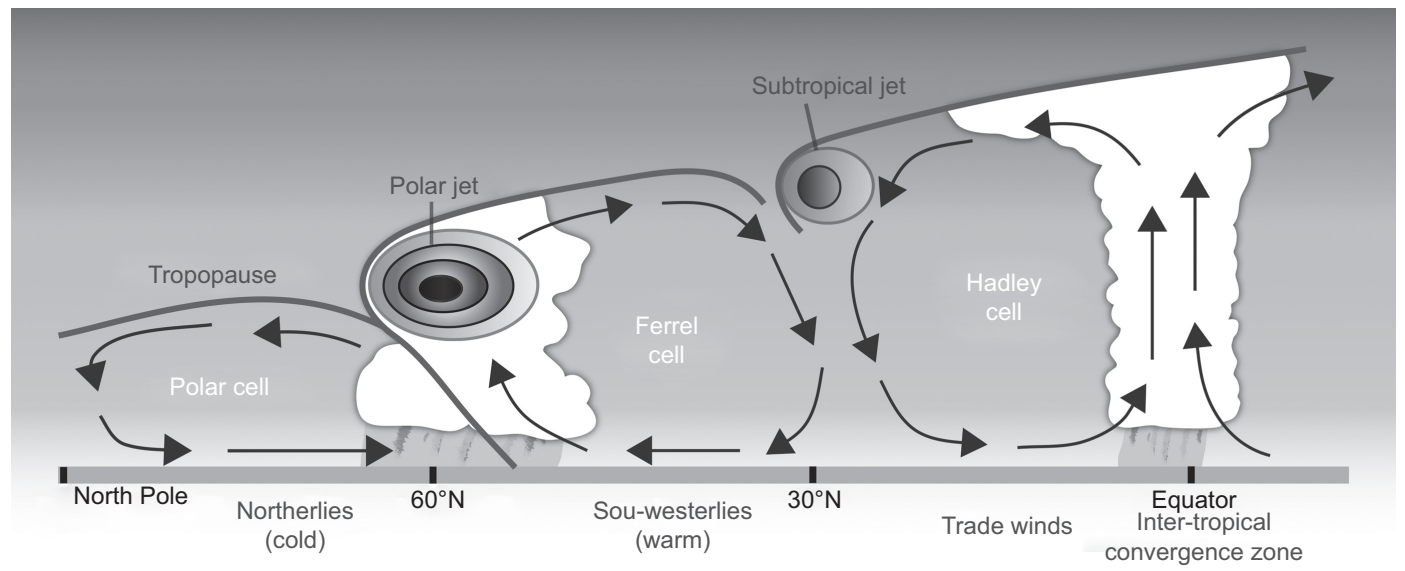

Figure 2. The relative positions of polar and sub-tropical jets and their associated air movements. Reproduced from National Oceanic and Atmospheric Administration, http://www.srh.noaa.gov/jestream/global/jet.htm (accessed 1 February 2014) fundamental atmospheric knowledge that assists in assessing the likely future behaviour of extreme rainfall and to validate the output from physically based models, such as global or regional climate models (GCMs or RCMs).

Global climate models are effective at reproducing the largescale atmosphere-ocean responses for the recent and past climate, giving confidence in probabilistic future projections (e.g. Murphy et al., 2009). Computational costs limit GCMs to a grid spacing of around $100-150 \mathrm{~km}$, resulting in powerful representation of global scale circulation responses and continental rainfall or temperature patterns, but less effective representation (Rummukainen, 2010) at the regional and local scales required by most decision makers. As model construction and processing power are constantly evolving, so too is the development of higher resolution grid GCMs, greater complexity in atmospheric processes and improved representation over high elevations. Figure 3 illustrates the differences in the representation of regional mean winter daily rainfall between the different model scales and gridded observations.

Regional climate models employ boundary conditions derived from the downscaled outputs of GCMs to run atmospheric responses on a smaller scale (approximately 4-36 km). However, the resultant models cannot always reproduce the atmospheric processes within the model layers, as interactions between largescale flow and the topographical features are not always well defined by the boundary conditions. A new development is the use of global climate models comprising uniform and variable Voronoi tessellated grids, centred over the region of interest at a grid spacing of $15 \mathrm{~km}$, expanding out to $120 \mathrm{~km}$ across the rest of the globe (Skamarock et al., 2012), removing the influence of boundary conditions and improving the representation of finescale processes (refer to Figure 4). Further developments to refine grid scales below $4 \mathrm{~km}$, as employed for numerical weather predictions, are also being developed to improve temporal and spatial representation of convective rainfall. These refinements are particularly important in regions that are sensitive to extreme convective rainfall such as Boscastle in 2004. In the absence of high-resolution data, RCM outputs can be downscaled to the local scale using statistical techniques from simple linear relationships with their observed counterpart, through to more complex additive models based on well-represented atmospheric processes (e.g. Jones et al., 2013a).

A commonly cited reason for not adapting infrastructure design to cope with a changing climate, and particularly enhanced extreme events, is the level of uncertainty in future estimates based on climate projections (Overpeck, 2000), and imbalance between the outlay costs and potential benefits of the actions (Wilby and Dessai, 2010). Detection of real changes in observed climate responses is therefore essential to facilitate appropriate adaptation action to be taken by decision makers; some successful detection approaches are now appearing (Done et al., 2013; Holland and Bruyère, 2014), but the lack of community consensus makes it difficult to make decisions other than understanding the type of risk involved. Understanding the current mechanisms of failure and sources of risk is likely to highlight that the uncertainty surrounding future projections is the least important variable in medium to long-term design decisions. Further, identifying the causes of flooding will demonstrate that design approaches based only on the annual maximum daily rainfall total are not always appropriate and leave little scope for flexible adaptation in the future. 

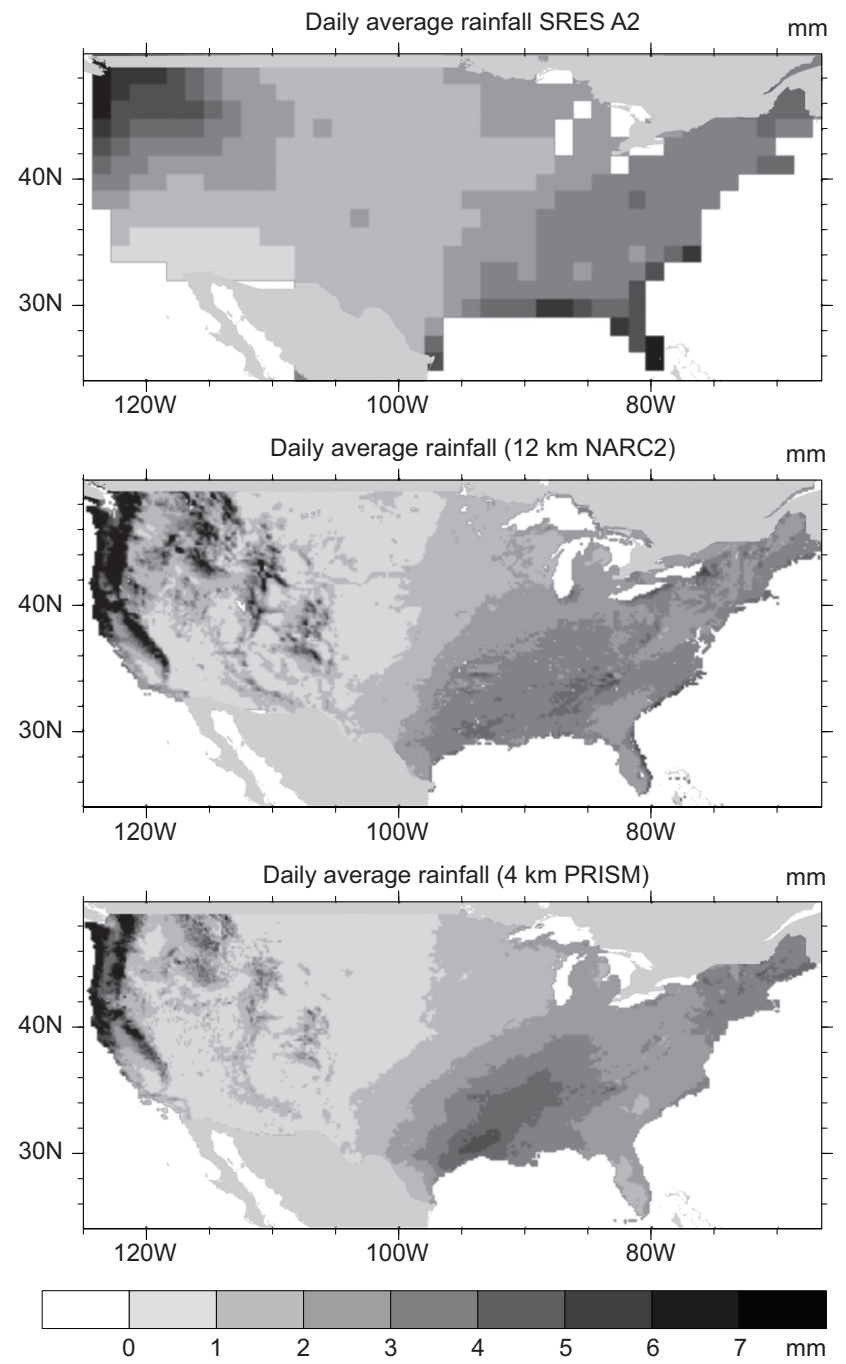

Figure 3. Mean winter daily rainfall totals from $100 \mathrm{~km} \mathrm{GCM}, 12$ $\mathrm{km} \mathrm{RCM} \mathrm{compared} \mathrm{with} 4 \mathrm{~km}$ gridded observations. (Refer to Done et al. (2013) for information on data)

\section{Observed changes in UK extreme rainfall}

Recent research has focused on changes in observed extreme daily rainfall and on the governing processes to anticipate what is likely to occur with future changes in the climate. Much attention has been given to the likely return period (or annual probability) of extreme rainfall, whether in the press or in the design process, and several studies examined the annual maximum daily totals and their evolution over the past century (e.g. Jones et al., 2013b; Maraun et al., 2008). Using up to 600 Met Office daily observation stations across the UK and Northern Ireland, these studies concurred that the intensity of the most extreme events is changing, with increases in multiday maxima over the north and west of the UK and decreases in single day annual maxima over the south and east. Seasonal evaluations demonstrated that the largest widespread changes in intensity are in winter rainfall, while north and western regions are also experiencing increases in spring and autumn rainfall intensity. Results for the summer were variable across the UK but pointed to an increase in the most intense maxima and a slight decrease in very heavy rainfall.

One of the drivers of flooding is high-intensity rainfall over ground that is saturated from several antecedent events. Yet few, if any, previous studies have examined the frequency of extreme rainfall events, especially their tendency to occur in rapid succession over a period of weeks (clustering) or in cycles over several years. A summary is presented below of a novel statistical technique that is informed by atmospheric and oceanic drivers to establish when extreme rainfall occurs throughout the year and the inter-annual variability. By characterising extreme rainfall occurrences and intensity in this way it is possible to interpret current extreme rainfall behaviour in the context of natural climatic variability and climate change. The use of climatological observation series that are well represented in climate models means that climate projections may be statistically downscaled from RCMs or GCMs and facilitate more effective hydrological adaptation action planning.

Figure 5 illustrates the seasonal variability in rainfall occurrences and their associated intensity for two regions: North Highlands and Islands of Scotland (Figure 5(a)) and southeast England (Figure 5(b)). The top row shows the relative frequency (frequency density) of rainfall occurrences per day of the year, whereas the solid lines indicate rainfall maxima and the dashed lines indicate mean daily rainfall. Vertical lines indicate the first day of March, June, September and December. There is a distinctive seasonal pattern in extreme daily rainfall occurrences, with the lowest frequency of extreme events during the spring, and considerable differences between the two regions. The frequency of extreme daily rainfall in the North Highlands and Islands is dominated by large autumn and winter frontal systems, whereas southeast England has two 'peaks' in frequency relating to summertime convective systems and autumnal frontal systems. In contrast, mean daily rainfall occurrences for both regions are most frequent during the winter and less frequent during summer months.

There is also a seasonal pattern in rainfall intensity (Figure 5 bottom row) illustrated by the standardised regional mean daily rainfall (dashed lines) and standardised regional median annual maximum rainfall (solid lines). Individual station daily rainfall and maxima were standardised by the station mean daily or median annual maximum rainfall (1961-1990), respectively, to remove orographic and exposure effects. The regional values were then calculated from the weighted mean of 


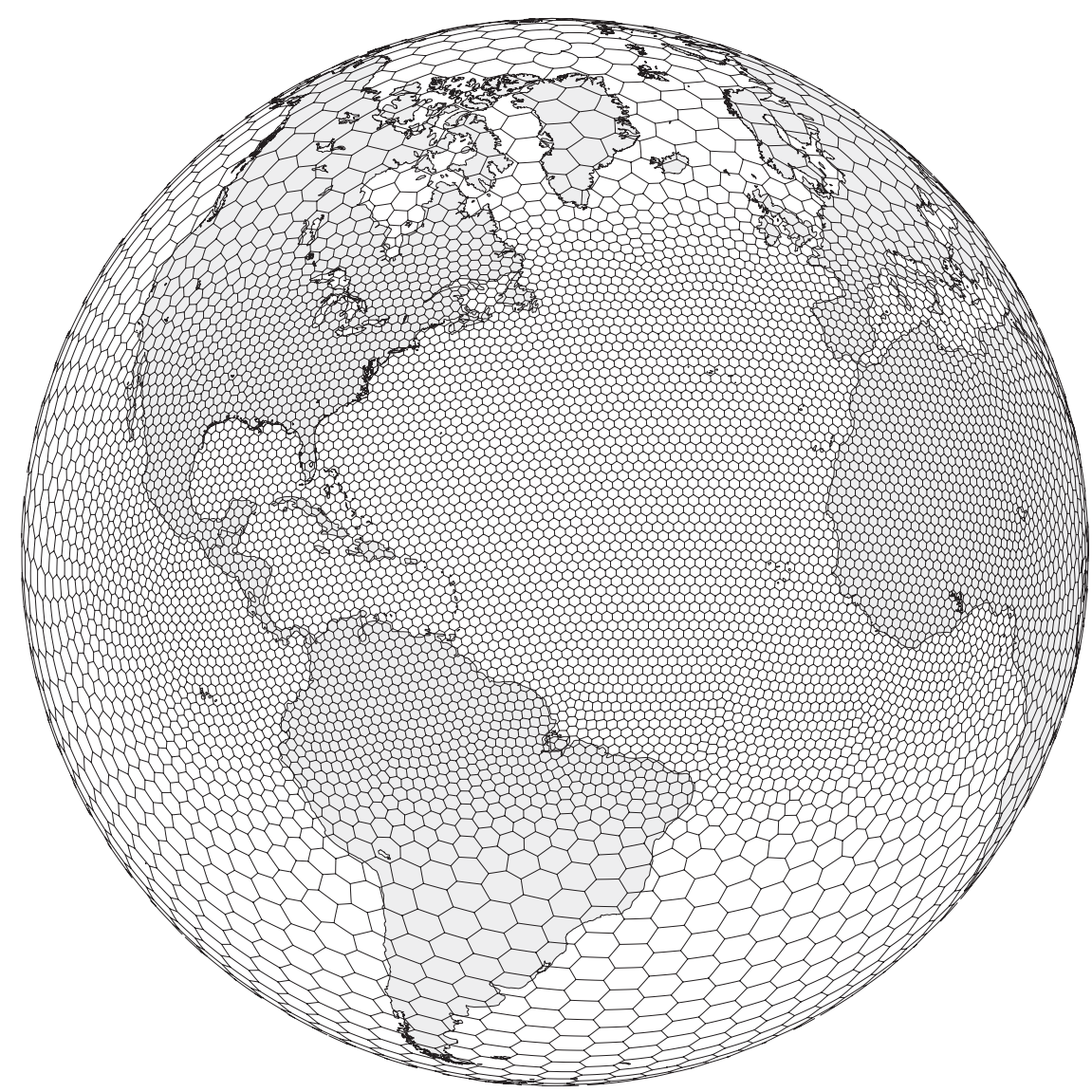

Figure 4. Model prediction across scales variable-resolution Voronoi mesh with 10242 grid cells centred over North America. Developed jointly by the National Center for Atmospheric Research and Los Alamos Laboratory. Further information in Skamarock et al. (2012) all stations in the region, with weighting based on the station record length. Although there is a strong seasonal cycle in mean daily rainfall intensity, related to autumn and winter frontal systems, there is little variation in the intensity of daily rainfall maxima throughout the year. Marginal peaks in extreme event intensity (e.g. September in North Highlands and Islands) do not coincide with peaks in the frequency of extreme daily rainfall occurrences.

Complex statistical linear models examine the natural variability in these multimodal seasonal patterns and quantify apparent trends in the observations. This is the first time that such models have been used to identify changes in within-year clustering, given the prevailing atmospheric conditions over the last 110 years, and so to distinguish trends from randomness. Figure 6 illustrates some results from the statistical models for the same regions as Figure 5, North Highlands and Islands (Figure 5(a)) and southeast England (Figure 5(b)). Figures on the right are the probability of an extreme event on each day of the year for successive 25-year periods, showing an evolution towards the highest probability occurring later in the year. Figures on the left chart the highest probability of extreme events per year, with a smooth spline trend line and an estimate of the period with the highest probability of an extreme event.

There is considerable natural variability in the seasonal patterns of extreme daily rainfall occurrences from year to year. However, there is a change in the timing of the most extreme events (later in autumn in the two illustrated regions). There is also a statistically significant increase in the probability of an extreme rainfall event during the period of the year when most events occur. In other words, there is a higher probability of several extreme rainfall events occurring in rapid succession; this has considerable implications for flood risk management both now and with respect to future climate change. The principal conclusions of relevance to flood risk management are as follows. 

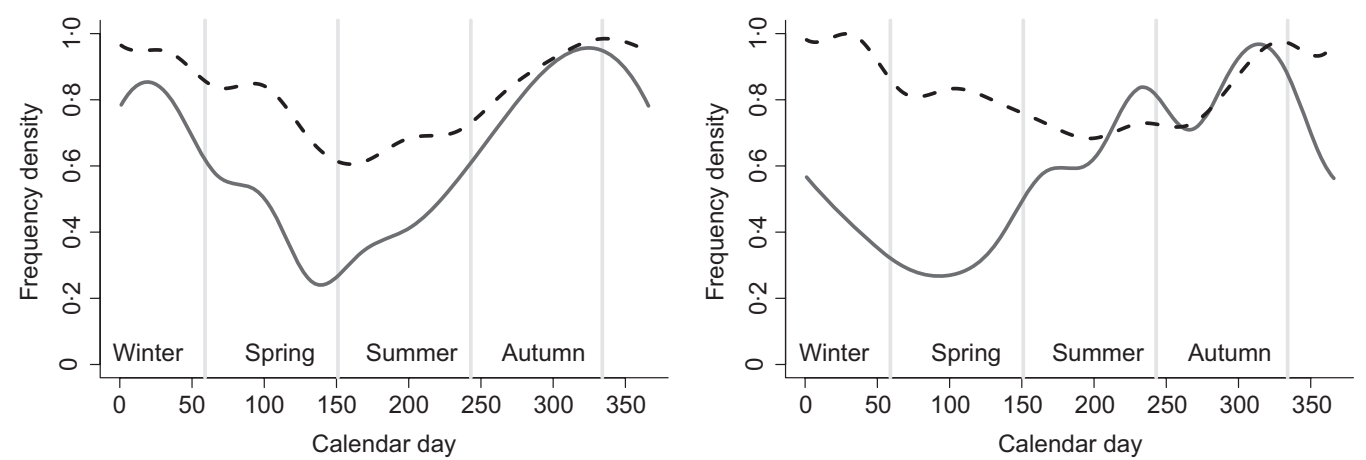

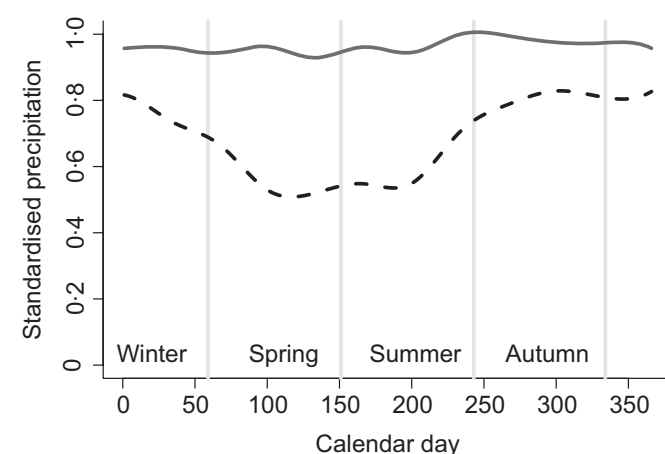

(a)

Figure 5. Examples of seasonal pattern of extreme rainfall occurrences (solid line) and mean rainfall occurrences (dashed line) for (a) North Highlands and Islands and (b) southeast England; and

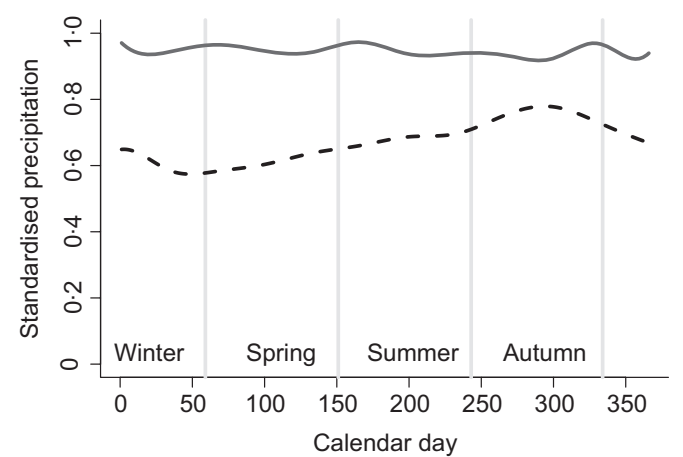

(b)

standardised extreme rainfall intensity (solid line) and mean daily rainfall intensity (dashed line) for the same locations. Vertical lines denote 1 March, 1 June, 1 September and 1 December
Extreme and very heavy rain days in the UK display a distinctive seasonal pattern in the occurrences throughout the year, with regional differences in the timing of the peak period (refer to Figure 5 for examples).

- The probability of extreme and very heavy rainfall events within those peak periods is increasing, resulting in several extreme rainfall events occurring in rapid succession.

- The timing of the peak period is shifting towards more autumnal extreme rainfall events from summer, in the southeast of the UK, or winter, in the northwest of the UK.

- The timing of the most intense rainfall events does not necessarily coincide with their seasonal pattern of occurrence. That is the annual maximum may occur earlier in the summer or later in the winter, dependent on location, than the period when most extreme daily rainfall events tend to occur (refer to Figure 5).

- The intensity of multi-day maxima is increasing over the north and west of the UK; these changes are particularly apparent in winter rainfall and emergent in spring and autumn rainfall (Jones et al., 2013b; Maraun et al., 2008).

- The most extreme convective summer rainfall events are increasing in intensity, while moderately heavy to heavy summer rainfall is decreasing slightly (Jones et al., 2013b).
There is a strong dependency of UK extreme daily rainfall on diurnal air temperature range and sea surface temperature, which is likely to correspond with future increases in frequency and intensity under climate change (Jones et al., 2013a).

\section{Application to flood hydrology}

Increases in the frequency or intensity of rainfall maxima are of great consequence, dependent on the season, location and area of risk. For instance, increases in autumn maxima may have considerable impacts on surface runoff if rainfall events occur after harvesting and lead to rural flooding and submerged highway drainage systems. Summertime increases in event intensity, particularly in combination with a hotter and drier future climate, may have devastating impacts on future floods where clay soils may be desiccated and unable to absorb rapid moisture, leading to enhanced runoff. In any season, increased urbanisation coupled with more intense rainfall will lead to increases in urban flooding. Even where flooding may not be an issue, an enhanced hydrological cycle will cause an increase in 'first flush' pollution and so have a detrimental impact on river water quality. The importance of diurnal air temperature range and sea surface temperature confirms postulations that 

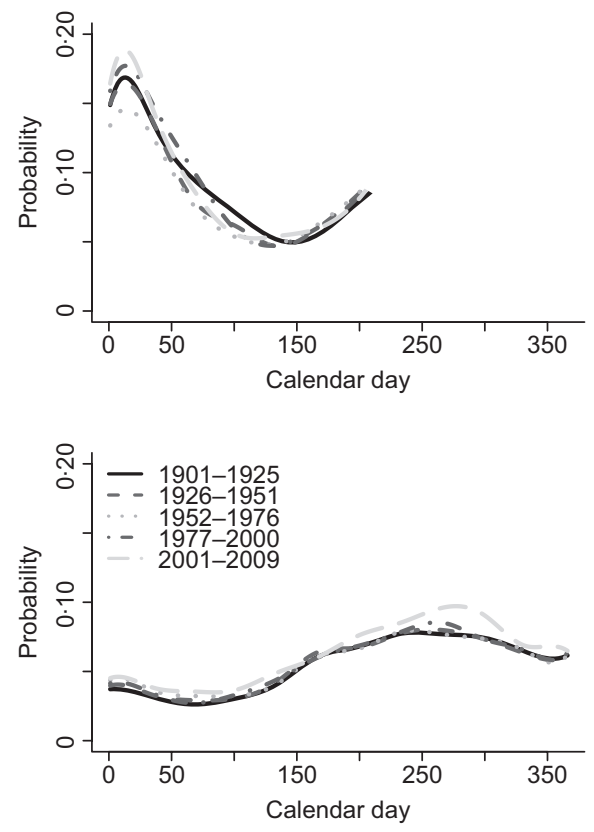

Figure 6. (Left) Examples of changes in the probability of extreme rainfall throughout the year by 25-year period for (a) North Highlands and Islands and (b) southeast England. Vertical lines denote 1 March, 1 June, 1 September and 1 December. (Right)

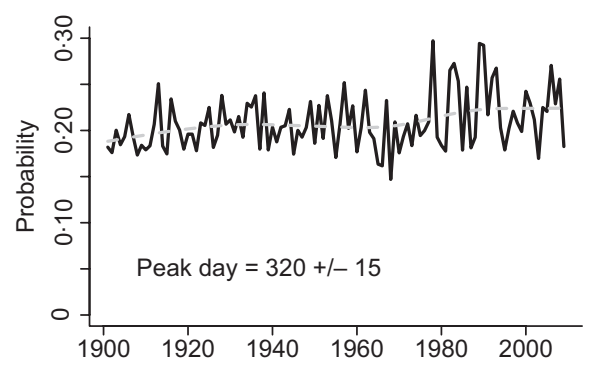

(a)

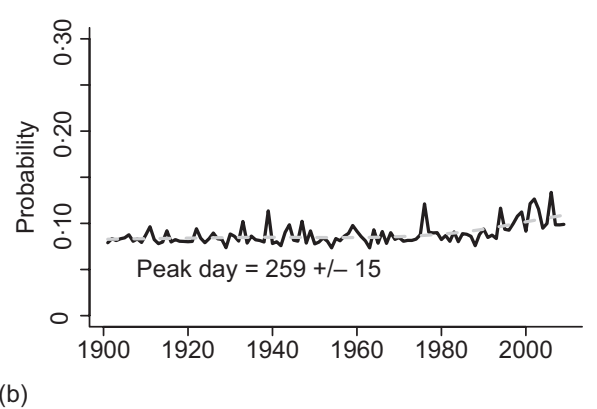

Maximum annual probability of an extreme event (black line) and smooth spline trend (dashed grey line) for (a) North Highlands and Islands and (b) southeast England future years will bring more intense and more frequent rainfall (IPCC, 2013).

Allowance for non-stationarity in regional rainfall or flood estimates has been addressed by the research community, but is far from common practice in hydrological design. Most analyses of extreme rainfall have focused on traditional extreme value analyses to estimate the likely return frequency of specific events. Climate change adaptation plans are often unclear with respect to projected changes in extreme rainfall as climate models often underestimate extreme rainfall. The statistical model described above can be used in combination with climate projections to examine the seasonal and multiannual fluctuations in rainfall maxima, and quantify the likely impacts from changes in extreme daily rainfall for use in design. Examination of inter and intra-annual variability in event frequency, timing of occurrences and intensity demonstrates that focusing only on traditional extreme value analyses will lead to a less resilient flood protection system. Recent research highlights that systems with limited storage are vulnerable to clustering in extreme rainfall arrival, and so are susceptible to failure. Projected climate changes of increasingly frequent and intense extreme rainfall will put piped sewerage systems and enclosed waterways under further pressure and lead to more frequent flooding.
It is no longer practicable to design empirically using tools established over the past century and it is important to recognise that there is not a 'one-size-fits-all' solution for flood management. Improved resilience to current and future flooding requires a range of flood management solutions that respond to all sources and pathways of flooding, and, in particular, multiple events within a short time. Such solutions will include more traditional hard-engineered flood defences where appropriate or necessary, but must also include innovative solutions such as coastal realignment, rural integrated runoff management, and greater use of sustainable urban drainage systems to attenuate and store runoff. The latter bring their own challenges with respect to the responsibility for maintenance, but also create amenities such as enhanced recreational areas and wildlife habitats. A further benefit is that these solutions are flexible, allowing the solution for near or short-term impacts to be expanded or altered as the climate and other challenges, for example increased urbanisation, evolve.

All engineered systems are designed to withstand forces up to a target level, beyond which failure is inevitable. However, given changes in extreme rainfall patterns, such an approach may no longer be adequate or practical. Brown et al. (2012) advocate assessing the likely consequences of credible changes in the climate information used for design, then incorporating 
flexibility to accommodate the impacts. Such an approach requires collaboration to identify the sources of vulnerability, potential mechanisms to improve resilience (The Royal Society, 2014). Some multi-disciplinary initiatives have been established to facilitate research to improve societal resilience to extreme weather, but these are often of finite duration due to funding constraints (e.g. Crew, 2012; SmarTest, 2013). The Engineering for Climate Extremes Partnership (ECEP, 2014) is a newly formed interdisciplinary partnership bringing together engineering, scientific, cultural, business and government expertise to develop robust, well-communicated predictions and advice on the impacts of weather and climate extremes in support of society. On-going collaborative research and knowledge dissemination are at the heart of this partnership to develop resilient responses to current and future climate extremes.

Information on the probable changes in extreme rainfall frequency and intensity is urgently required by those designing any permanent infrastructure, but is not currently available. Enhancing climate projections for use in planning and decision making requires a combination of higher resolution climate models, together with improved statistical approaches and greater understanding of the processes driving extreme weather events. By characterising the drivers for use in statistical downscaling, it is possible to improve projections of future extreme rainfall and hence the reliability of information used in design. Presenting this information in a useable format for engineers and other decision makers is of primary importance, and is the focus of on-going research and outreach programmes. In this regard, ECEP offers an opportunity to interact more fully with, and improve dialogue between, the engineering and science communities.

\section{Acknowledgements}

This work was part of a Natural Environment Research Councilfunded postgraduate research studentship NE/G523498/1 (20082012). The National Center for Atmospheric Research is sponsored by the National Science Foundation (NSF); this work was also partially supported by NSF EASM grant S1048841. With many thanks to Hayley Fowler, Chris Kilsby and Stephen Blenkinsop who supervised the postgraduate research, and to Greg Holland and James Done for discussions that helped to improve this paper. Thanks are also due to Michael Duda, Ming Ge and Terri Hamner for assistance with illustrations.

\section{REFERENCES}

ABI (Association of British Insurers) (2014) Insurance Bill for Storm and Flood Damage Over Christmas 2013 and the New Year Period Set to Cost $£ 426$ Million. Association of British Insurers, London, UK. See https://www.abi.org.uk/News/ News-releases/2014/01/Insurance-bill-for-storm-and-flooddamage-over-Christmas-2013-and-New-Year-period-setto-cost-426m (accessed 18/02/2014).
Adaptation Sub-Committee Secretariat (2014) Policy Note: Flood and Coastal Erosion Risk Management Spending.

Adaptation Sub-Committee Secretariat, London, UK.

Blöschl G and Montanari A (2010) Climate change impacts throwing the dice? Hydrological Processes 24(3): 374-381, http://dx.doi.org/10.1002/hyp.7574.

Brackenridge GR (2011) Global Active Archive of Large Flood Events. The Flood Observatory, University of Colorado, Boulder, CO, USA. See http://floodobservatory.colorado. edu/index.html (accessed 10/12/2012).

Brown C, Ghile Y, Laverty M et al. (2012) Decision scaling: Linking bottom-up vulnerability analysis with climate projections in the water sector. Water Resources Research 48(9):WR09537, http://dx.doi.org/10.1029/2011WR011212.

Crew (Community Resilience to Extreme Weather) (2012) http:// www.extreme-weather-impacts.net/twiki/bin/view/Main/ WebHome (accessed 11/12/2014).

Defra (Department for Environment, Food and Rural Affairs) (2012) UK Climate Change Risk Assessment: Government Report. The Stationery Office, London, UK.

Done JM, Holland GJ, Bruyère CL et al. (2013) Modeling highimpact weather and climate: lessons from a tropical cyclone perspective. Climate Change 129(3/4): 381-395

ECEP (Engineering for Climate Extremes Partnership) (2014) http://www.ecep.ucar.edu. Accessed 1 February 2015.

Holland G and Bruyère CL (2014) Recent intense hurricane response to global climate change. Climate Dynamics $\mathbf{4 2}$ : 617-627, http://dx.doi.org/10.1007/s00382-013-1713-0.

IPCC (Intergovernmental Panel on Climate Change) (2012) Managing the Risks of Extreme Events and Disasters to Advance Climate Change Adaptation (CB Field CB, Barros $\mathrm{V}$, Stocker TF et al. (eds)). Cambridge University Press, Cambridge, UK and New York, NY, USA.

IPCC (2013) Climate Change 2013: The Physical Science Basis. Contribution of Working Group I to the Fifth Assessment Report of the Intergovernmental Panel on Climate Change (Stocker TF, Qin D, Plattner GK et al. (eds)). Cambridge University Press, Cambridge, UK and New York, NY, USA, http://dx.doi.org/10.1017/CBO9781107415324.

Jones MR, Blenkinsop S, Fowler HJ et al. (2013a) Generalized Additive Modelling of Daily Precipitation Extremes and their Climatic Drivers. National Center for Atmospheric Research, Boulder, CO, USA, NCAR Technical Note NCAR/TN-501+STR.

Jones MR, Fowler HJ, Kilsby CG et al. (2013b) An assessment of changes in seasonal and annual extreme rainfall in the UK between 1961 and 2009. International Journal of Climatology 33(5): 1178-1194, http://dx.doi.org/10.1002/ joc. 3503 .

Krebs J, Dlugolecki A, Fankhauser S et al. (2010) How Well Prepared is the UK for Climate Change? Committee on Climate Change, London, UK. See http://www.theccc.org. uk (accessed 18/02/2014). 
Krebs J, Dlugolecki A, Fankhauser S et al. (2011) Adapting to Climate Change in the UK: Measuring Progress.

Adaptation Sub-Committee, London, UK. See http://www. theccc.org.uk (accessed 10/12/2012).

Leonard M, Westra S, Phatak A et al. (2014) A compound event framework for understanding extreme impacts. Wiley Interdisciplinary Reviews on Climate Change 5(1): 113-128, http://dx.doi.org/10.1002/wcc.252.

Mandelbrot BB and Wallis JR (1968) Noah, Joseph, and operational hydrology. Water Resources Research 4(5): 909-918, http://dx.doi.org/10.1029/WR004i005p00909.

Maraun D, Osborn TJ and Gillett NP (2008) United Kingdom daily precipitation intensity: improved early data, error estimates and an update from 2000 to 2006. International Journal of Climatology 28(6): 833-842.

Met Office (2011) United Kingdom. Climate: Observations, Projections and Impacts. Met Office, Exeter, UK.

Milly PCD, Betancourt J, Falkenmark M et al. (2008) Climate change: Stationarity is dead: Whither water management? Science 319(5863): 573-574, http://dx.doi.org/10.1126/ science. 1151915.

Min SK, Zhang X, Zwiers FW et al. (2011) Human contribution to more-intense precipitation extremes. Nature 470: 378-381.

Munich RE (2013) Floods Dominate Natural Catastrophe Statistics in First Half of 2013. Munich RE, Munich, Germany. See http://www.munichre.com/en/mediarelations/publications/press-releases/2013/2013-07-09press-release/index.html (accessed 25/02/2014).

Murphy J, Sexton D, Jenkins G et al. (2009) Climate Change Projections. Met Office Hadley Centre, Exeter, UK.

O'Connell PE and Hall J (2007) Earth systems engineering: turning vision into action. Proceedings of the Institution of Civil Engineers - Civil Engineering 160(3): 114-122, http:// dx.doi.org/10.1680/cien.2007.160.3.114.

Overpeck JT (2000) Climate change: The hole record. Nature 403: 714-715, http://dx.doi.org/10.1038/35001697.

Oxford English Dictionary (OED) Online (2014) Oxford University Press. Availbale at: http://www.oed.com/view/ Entry/163619?redirectedForm $=$ resilience $($ accessed 13/02/ 2014).

Rosenzweig C, Solecki WD, Hammer SA et al. (2011) Climate Change and Cities: First Assessment Report of the Urban Climate Change Research Network. Cambridge University Press, Cambridge, UK.

Rummukainen M (2010) State-of-the-art with regional climate models. WIREs Climate Change 1(1): 82-96, http://dx.doi. org/10.1002/wcc.8.

Skamarock WC, Klemp JB, Duda MG et al. (2012) A multiscale nonhydrostatic atmospheric model using centroidal Voronoi tesselations and C-grid staggering. Monthly Weather Review 140(9): 3090-3105, http://dx.doi.org/10. 1175/MWR-D-11-00215.1.
SmarTest (2013) http://www.floodresilience.eu (accessed 11/12/ 2014).

Stern NH (2007) The Economics of Climate Change: The Stern Review. Cambridge University Press, Cambridge, UK.

Sundermann L, Schelske $\mathrm{O}$ and Hausmann $\mathrm{P}$ (2013) Mind the Risk - A Global Ranking of Cities Under Threat from Natural Disasters. Swiss Reinsurance Company, Zurich, Switzerland. See http://media.swissre.com/documents/ Swiss_Re_Mind_the_risk.pdf (accessed 18/02/2014).

The Royal Society (2014) Resilience to extreme weather. The Royal Science Policy Centre report 02/14, ISBN: 978-178252-113-6. Availbale at: https://royalsociety.org/(cedilla)/ medi/policy/projects/resilience-climate-change/resilinecefull-report.pdf (accessed 01/12/2014).

Trenberth KE (2011) Changes in precipitation with climate change. Climate Research 47(nr1-2): 123-138.

Wilby RL and Dessai S (2010) Robust adaptation to climate change. Weather 65(7): 180-185, http://dx.doi.org/10.1002/ wea.543.

Zhang X, Alexander L, Hegerl GC et al. (2011) Indices for monitoring changes in extremes based on daily temperature and precipitation data. Wiley Interdisciplinary Review of Climate Change 2(2): 851-870, http://dx.doi.org/10.1002/ wcc. 147 .

\section{WHAT DO YOU THINK?}

To discuss this paper, please email up to 500 words to the editor at journals@ice.org.uk. Your contribution will be forwarded to the author(s) for a reply and, if considered appropriate by the editorial panel, will be published as discussion in a future issue of the journal.

Proceedings journals rely entirely on contributions sent in by civil engineering professionals, academics and students. Papers should be 2000-5000 words long (briefing papers should be $1000-2000$ words long), with adequate illustrations and references. You can submit your paper online via www.icevirtuallibrary.com/content/journals, where you will also find detailed author guidelines. 